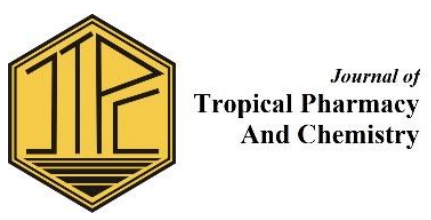

\title{
PERAN HOMEPHARMACYCARE PADA PASIEN DIABETES MELLITUS TIPE II PROLANIS TERHADAP TINGKAT KEPATUHAN DAN KEBERHASILAN TERAPI DI BP SENTRA MEDIKA LEBAKSIU TEGAL
}

\author{
Mita Rodiyatun Najiha*, Wahyu Utaminingrum, Much Ilham Novalisa Aji Wibowo \\ Universitas Muhammadiyah Purwokerto \\ *Corresponding Author: mithaazz.medikafarma2013@gmail.com
}

\begin{abstract}
Diabetes mellitus disease (DM) is chronic diseases due to the increase of glucose concentration in the body. The compliance and successful treatment of diabetes are needed to prevent complications. The patients' compliance in using the medicine is an important factor of the successful therapy. One of the most comprehensive interventions for DM patients is Home Pharmacy Care. This study aims to determine the effect of Home Pharmacy Care role in patients with diabetes mellitus in increasing the compliance and successful therapy. This research is pre experimental research conducted at Bp Sentra Medika Clinic and counseling at home respondents in Lebaksiu, Tegal with using the method of one group pretest posttest design. Purposive sampling method is used in this research and got 35 respondents. Measurements were made using the MMAS-8 (pretest-postest) and pill count instrument to determine the patient's compliance level and the glucotest to measure the success of therapy characterized by blood sugar levels. Statistics test uses Wilcoxon and Mc Nemar to determine the effect of provision of Home Pharmacy Care intervention on compliace and successful therapy level. The results showed that a total of 20 patients (57\%) comliance to MMAS-8 and pill count scores and a total of 20 patients (57\%) of successful treatment were achieved based on controlled blood glucose levels. Statistical test showed that there was a significant difference between before and after intervention marked with the value of $p$ value of both tests was 0,000 so that there is an effect of giving Home Pharmacy Care toward the improvement of compliance and successful therapy.
\end{abstract}

Keywords : diabetes mellitus, homepharmacycare, prolanis, compliance and successful therapy level.

\begin{abstract}
ABSTRAK
Penyakit Diabetes mellitus (DM) termasuk penyakit yang bersifat kronis akibat terjadi peningkatan konsentrasi glukosa didalam tubuh. Pengobatan diabetes yang baik dan patuh menjadi hal yang sangat penting dilakukan untuk mencegah komplikasi. Salah satu intervensi yang komprehensif untuk pasien penyakit degeneratif adalah home pharmacy care. Tujuan Penelitian untuk mengetahui pengaruh peran home Pharmacy Care pada pasien diabetes melitus dalam meningkatkan kepatuhan dan keberhasilan terapi. Metode Penelitian: Penelitian ini merupakan penelitian pra experimental yang dilakukan di Bp Sentra Medika dan konseling di rumah masing-masing responden di Kecamatan Lebaksiu Kabupaten Tegal dengan metode one group pretest posttest design. Sampel diperoleh dengan metode purposive sampling dan didapat 35 responden. Pengukuran dilakukan menggunakan instrumen kuesioner MMAS-8 (pretest-postest) dan pill count untuk mengetahui tingkat kepatuhan pasien serta glucotest untuk mengukur keberhasilan terapi yang ditandai dengan nilai kadar gula darah. Uji statistik menggunakan Wilcoxon dan Mc Nemar untuk mengetahui pengaruh dari pemberian intervensi home pharmacy care terhadap tingkat kepatuhan dan keberhasilan terapi. Hasil penelitian menunjukkan bahwa sejumlah 20 pasien (57\%) patuh berdasarkan skor MMAS-8 dan pill count dan sejumlah 20 pasien (57\%) keberhasilan terapi tercapai berdasarkan nilai kadar gula darah terkontrol. Kesimpulan: Uji statistik menunjukkan ada perbedaan yang signifikan antara sebelum dan sesudah pemberian intervensi yang ditandai dengan nilai $p$ value kedua uji adalah 0,000 sehingga pemberian home pharmacy care berpengaruh terhadap peningkatan kepatuhan dan keberhasilan terapi.
\end{abstract}


Pengaruh ekstrak etanol daun jambu air (Syzygium aqueum (burm f.)Alston) terhadap glukosa darah, ureum dan kreatinin tikus putih (rattus norvegicus)

Kata Kunci: diabetes mellitus, homepharmacycare, prolanis, tingkat kepatuhan dan keberhasilan terapi

DOI: https://doi.org/10.25026/jtpc.v4i2.134

\section{PENDAHULUAN}

Diabetes melitus merupakan salah satu penyakit yang sudah tidak asing lagi di kalangan masyarakat luas. Penyakit ini sudah banyak dikenal dan hampir dialami oleh sebagian masyarakat di dunia, walaupun terkadang masyarakat lebih mengenal penyakit ini dengan sebutan "Penyakit Kencing Manis". Hal ini dapat dibuktikan melalui data dari International Diabetes Federation (IDF) yang menyatakan bahwa terdapat 415 juta orang hidup dengan diabetes pada tahun 2015 yang diperkirakan akan meningkat sebesar 10,4\% dengan jumlah 642 juta penderita pada tahun 2040 [1].

Di indonesia khususnya, prevalensi penderita diabetes masih dinyatakan tinggi. Hal ini dibuktikan berdasarkan data terbaru yang di tunjukkan oleh Perkumpulan Endokronologi (PERKENI) pada tahun 2015 yang menyatakan bahwa jumlah penderita diabetes melitus di Indonesia telah mencapai 9,1 juta orang dan menempati peringkat ke 5 teratas diantara negara-negara dengan jumlah penderita DM terbanyak di dunia dan juga World Health Organizatiton (WHO) memperkirakan pada tahun 2030 jumlah penderita DM akan meningkat menjadi sekitar 21,3 juta orang [2].

Di wilayah jawa tengah khususnya, tingginya prevalensi penderita diabetes dapat di lihat berdasarkan profil kesehatan provinsi jawa tengah tahun 2014 yang menyatakan bahwa Diabetes Mellitus menempati urutan proporsi terbesar kedua setelah Hipertensi dari seluruh PTM (penyakit tidak menular) yang dilaporkan dengan prevalensi penderita Diabetes mellitus sebesar 16,53 $\%$. Hasil survey WHO pada tahun 2010 yang menyatakan bahwa penyakit tersebut merupakan $63 \%$ penyebab kematian di seluruh dunia dengan membunuh 36 juta jiwa per tahun.

Tingginya prevalensi diabetes mellitus yang terus meningkat setiap tahunnya, menuntut tenaga kesehatan untuk melakukan evaluasi dalam pelayanan kesehatan terkait terapi Diabetes Mellitus. Banyak kejadian dari sejumlah banyak pasien Diabetes Mellitus hanya beberapa persen saja yang berhasil dalam pelaksaanaan pengobatan. Padahal pengobatan diabetes yang baik dan patuh menjadi hal yang sangat penting dilakukan untuk mencegah komplikasi. Hal ini dapat disebabkan oleh beberapa faktor yang berpengaruh dalam pengobatan pasien. Kejadian tersebut mayoritas disebabkan karena dari diri pasien itu sendiri terkait gaya hidupnya yang kurang baik. Selain itu, berkaitan dengan kepatuhan dalam pengobatan yang kurang, baik secara farmakologi maupun non farmakologi terutama pada pasien yang sudah lansia. Menurut Pratiwi pada penelitiannya tahun 2007 ada umumnya penderita DM patuh berobat kepada dokter selama ia masih menderita gejala / yang subyektif dan mengganggu hidup rutinnya sehari-hari. Begitu ia bebas dari keluhan - keluhan tersebut maka kepatuhannya untuk berobat berkurang. Ketidakpatuhan ini sebagai masalah medis yang sangat berat [3]. 
Ada beberapa intervensi untuk menangani kejadian tersebut yang dapat dilakukan oleh seorang apoteker sebagai salah satu tenaga kesehatan dalam hal pelayanan kefarmasian pada pasien diabetes melitus, salah satunya adalah pelaksanaan sistem Home Pharmacy care, dimana sistem tersebut belum banyak diterapkan dalam pelayanan kesehatan. Dengan menerapkan Home Pharmacy Care, apoteker dapat lebih mendampingi pasien dalam pengobatannya karena apoteker dapat secara langsung melakukan review terkait pengobatan pasien, memberikan edukasi terkait penyakit dan cara pengobatannya dengan benar tujuan dan manfaatnya, melakukan konseling serta monitoring terhadap pengobatan pasien sehingga diharapkan dapat membantu tercapainya keberhasilan terapi.

Penelitian bertujuan untuk mengetahui pengaruh dari peran Home Pharmacy Care pada pasien diabetes mellitus tipe II PROLANIS di Bp Sentra Medika Lebaksiu Tegal terhadap tingkat kepatuhan dan keberhasilan terapi.

\section{METODE PENELITIAN}

Penelitian ini dilakukan pada bulan Mei sampai Juni 2017 di Bp Sentra Medika dan rumah masing-masing responden di Lebaksiu Tegal. Jenis penelitian yang digunakan dalam penelitian ini adalah penelitian pra experimental dengan desain penelitian one group pretest posttest design. Populasi dalam penelitian ini adalah pasien diabetes melitus yang terdaftar dalam program PROLANIS di Bp Sentra Medika. Pengambilan sampel dilakukan menggunakan teknik purposive sampling yang memenuhi kriteria inklusi dan tidak termasuk dalam kriteria eksklusi dan didapat 35 responden. Alat yang digunakan dalam penelitian ini yaitu Kuisioner MMAS-8 dan pill count untuk mengukur kepatuhan dan gluco-test untuk mengukur kadar gula darah .

Data yang diambil berupa demografi pasien seperti usia,jenis kelamin, pekerjaan, kepatuhan pasien berdasarkan kuisioner dan pill count serta nilai kadar gula darah pasien. Dari data yang dikumpulkan, kemudian dianalisis menggunakan analisis univariat untuk karakteristik responden seperti usia,jenis kelamin dan pekerjaan dan analisis bivariat yaitu uji wilcoxon untuk melihat pengaruh intervensi yang diberikan pada peningkatan kepatuhan dan uji mc nemar untuk melihat pengaruh intervensi yang diberikan pada peningkatan keberhasilan terapi.

\section{HASIL DAN PEMBAHASAN}

Jumlah pasien perempuan lebih dominan dibandingkan pasien laki-laki. Hal ini berkaitan dengan wanita lebih beresiko mengidap penyakit diabetes karena secara fisik wanita memiliki peluang peningkatan indeks masa tubuh yang lebih besar serta adanya hubungan faktor proses hormonal yang lebih besar dibandingkan laki-laki berkaitan dengan sindroma siklus bulanan (premenstrual syndrom), pasca-menopause yang membuat distribusi lemak tubuh menjadi mudah terakumulasi [4]. Perubahan hormonal yang terjadi pada perempuan yaitu dimana telah terjadi penurunan hormon estrogen dan progesteron akibat menopause.

Tabel 1. Distribusi Frekuensi Karakteristik Responden Berdasarkan Jenis Kelamin

\begin{tabular}{lll}
\hline Jenis kelamin & $\mathrm{n}$ & $\%$ \\
\hline Laki-laki & 14 & 40 \\
Perempuan & 21 & 60 \\
\hline Total & 35 & 100 \\
\hline
\end{tabular}

Sumber: Data Primer 2017 
Tabel 2. Distribusi Frekuensi Karakteristik Responden Berdasarkan Usia

\begin{tabular}{lll}
\hline Umur(Tahun) & $\mathrm{N}$ & $\%$ \\
\hline $50-60$ & 18 & 51,4 \\
$61-70$ & 14 & 40 \\
$71-80$ & 3 & 8,6 \\
\hline Total & 35 & 100 \\
\hline
\end{tabular}

Sumber: Data Primer 2017

Karakteristik responden berdasarkan usia,dapat diketahui bahwa kelompok usia 50-60 tahun lebih dominan. Hal ini karena pada rentang usia tersebut, termasuk kedalam golongan lanjut usia awal sehingga mulai mengalami penurunan fungsi organ termasuk pankreas yang mengakibatkan produksi insulin mulai menurun dan biasanya pada rentang usia tersebut pola hidup mulai menurun/kurang baik. Menurut Awad et al (2013) dalam penelitiannya menyatakan bahwa penderita diabetes terbanyak di rentang usia 51-60 tahun dan secara umum penderita paling banyak didapatkan pada usia 40-60 tahun [5]. Pasien dengan kelompok tidak bekerja lebih dominan jumlahnya dimana rata-rata adalah ibu rumah tangga. Hal ini karena pekerjaan berkaitan dengan aktivitas fisik, dimana pasien lebih dominan tidak bekerja dan hanya berdiam di rumah/melakukan aktivitas ringan sehingga kurangnya aktivitas fisik yang dapat lebih beresiko terkena diabetes.

Tabel 3. Distribusi Frekuensi Karakteristik Responden Berdasarkan Pekerjaan

\begin{tabular}{lll}
\hline Pekerjaan & N & $\%$ \\
\hline Bekerja & 7 & 20 \\
Tidak bekerja & 28 & 80 \\
\hline Total & 35 & 100 \\
\hline Sumber: Data Primer 2017 & &
\end{tabular}

Hal ini disebabkan karena aktivitas fisik yang kurang menyebabkan resistensi insulin sehingga dapat menyebabkan terjadinya penyakit diabetes. [6]. Menurut Zainuddin dkk (2015) penderita diabetes lebih dominan adalah ibu rumah tangga karena berkaitan dengan aktivitas fisik yang dilakukan oleh ibu rumah tangga kemungkinan besar lebih sedikit (ringan) dibanding orang yang memiliki aktifitas pekerjaan diluar rumah . Aktifitas fisik mengakibatkan insulin semakin meningkat sehingga kadar gula dalam darah akan berkurang. Jika insulin tidak mencukupi untuk mengubah glukosa menjadi energi maka akan timbul diabetes mellitus.

Tabel 4. Interpretasi Kepatuhan Sebelum dan Sesudah Intervensi berdasarkan mmas-8 dan pillcount

\begin{tabular}{cccc}
\hline & Patuh & $\begin{array}{c}\text { Tidak } \\
\text { patuh }\end{array}$ & $\mathrm{n}$ \\
\hline Sebelum Intervensi & 5 & 30 & 35 \\
Setelah Intervensi & 20 & 15 & 35 \\
\hline Total & & 35 & 100 \\
\hline
\end{tabular}

Sumber: Data Primer 2017

Tabel 4 menggambarkan bahwa ada perbandingan yang bermakna antara hasil kepatuhan sebelum intervensi dan sesudah intervensi dimana sebelum intervensi jumlah responden yang tidak patuh lebih dominan. Namun, hasil setelah intervensi menunjukkan jumlah responden yang masuk kedalam interpretasi patuh lebih dominan. Peningkatan ini disebabkan karena responden merasa diperhatikan dan dikontrol dalam menjalani terapinya sehingga lebih semangat dalam menjalankan terapinya karena merasa ada yang mengingatkan dan juga dapat secara langsung menanyakan apa yang dikeluhkan atau jika ada yang tidak paham terkait cara menjalani terapi diabetes yang baik dan benar karena ada apoteker yang lebih paham tanpa harus jauh-jauh ke dokter. Faktor faktor yang 
dapat mempengaruhi kepatuhan responden dalam mengkonsumsi obat antara lain Faktor lupa adalah faktor paling dominan, faktor kesengajaan tidak minum obat karena responden merasa bosan harus mengkonsumsi obat setiap hari secara terus menerus dalam jangka waktu panjang serta karena faktor takut efek samping obat. Selain faktor tersebut, faktor lain yang dapat mempengaruhi kepatuhan minum obat pasien adalah faktor regimen obat walaupun pasien yang mendapatkan terapi tunggal tidak selalu lebih patuh dari pasien yang mendapatkan terapi kombinasi, namun regimen obat dapat menjadi salah satu faktor yang dapat menyebabkan pasien.(Tabel 5)

Tabel 5. Deskripsi data kepatuhan ditinjau dari jenis terapinya

\begin{tabular}{llc}
\hline Jenis Obat Antidiabetik & Patuh & Tidak Patuh \\
\hline Tunggal & 14 & 8 \\
Kombinasi & 6 & 7 \\
\hline
\end{tabular}

Sumber: Data Primer 2017

Tabel 6. Interpretasi Keberhasilan Terapi Sebelum dan Sesudah Intervensi

\begin{tabular}{lccc}
\hline & Terkontrol & Tidak terkontrol & $\mathrm{n}$ \\
\hline Sebelum Intervensi & 14 & 8 & 35 \\
Setelah intervensi & 6 & 7 & 35
\end{tabular}

Sumber: Data Primer 2017

\begin{abstract}
Hasil diatas dapat menunjukkan bahwa terdapat perbedaan jumlah responden yang terkontrol dan tidak terkontrol antara sebelum dan sesudah intervensi dengan terjadi peningkatan pada jumlah responden yang terkontrol. Hal ini disebabkan karena adanya pengaruh dari peningkatan kepatuhan responden setelah pemberian intervensi sehingga dengan patuhnya responden dalam menjalani terapi baik farmakologi maupun non farmakologi dan menghindari
\end{abstract}

larangan maka akan menghasilkan kadar gula darah yang terkontrol. Selain harus patuh dalam terapi farmakologi, patuh terhadap terapi non farmakologi juga dapat meningkatkan keberhasilan terapi seperti menjaga pola makan dan aktifitas fisik yang cukup untuk mengontrol kadar gula darah dalam tubuh. Sehingga , kepatuhan pasien merupakan salah satu kunci untuk mencapai keberhasilan terapi [7]. Hal ini sejalan dengan Mulyani $R$ (2016) yang menyatakan bahwa adanya hubungan antara kepatuhan terapi dengan dengan keberhasilan terapi yang bersifat positif artinya semakin tinggi tingkat kepatuhan maka keberhasilan terapi semakin besar [8].

\section{Pengaruh Home Pharmacy Care terhadap Kepatuhan dan Keberhasilan Terapi}

Berdasarkan data dari Tabel 4 dan 6 yang kemudian dilakukan analisis, maka menunjukkan terdapat perbedaan yang sinifikan antara hasil sebelum dan sesudah pemberian intervensi. Sehingga, pemberian homepharmacycare yang dilakukan mampu meningkatkan kepatuhan dan keberhasilan terapi. Hal ini dapat dibuktikan melalui hasil analisis menggunakan SPSS dari keduanya menunjukkan nilai $p$ value 0,000 . Hal ini sejalan dengan Raditya dkk (2015) dalam penelitiannya bahwa adanya perbaikan pada kepatuhan, kadar gula darah, dan kualitas hidup pasien dibanding sebelum pemberian intervensi berupa pemberian home care oleh apoteker [9].

\section{KESIMPULAN}

Dari hasil penelitian dapat disimpulkan bahwa Terdapat pengaruh dari peran pemberian intervensi berupa home pharmacy care terhadap tingkat kepatuhan dan keberhasilan terapi pasien DM . 


\section{DAFTAR PUSTAKA}

[1]. IDF.(2015). Atlas diabetes seventh edition. Vancouver. International Diabetes Federation. Website: http://www.diabetesatlas.org/

[2]. PERKENI.(2015).Konsensus Pengelolaan dan Pencegahan Diabetes Melitus Tipe 2 Di Indonesia 2015. PB Perkeni

[3]. Aini, N., Fatmaningrum,W., dan Yusuf,A.(2011).Upaya meningkatkan perilaku pasien dalam tatalaksana diabetes melitus dengan pendekatan teori model behavioral system dorothy E. Johnson. Ners. Vol.6 (1)

[4]. Trisnawati, S \& Setyogoro, S. (2013). Faktor Resiko Kejadian Diabetes Melitus Tipe II di Puskesmas Kecamatan Cengkareng Jakarta Barat Tahun 2012. Jurnal Ilmiah Kesehatan. Volume 5, No 1

[5]. Awad, N., Yuanita, A., Karel, P.(2013). Gambaran Faktor Resiko Pasien Diabetes Mellitus Tipe II Di Poliklinik Endokrin Bagian/SMF FK-UNSRAT RSU Prof. Dr. R.D Kandou Manado Periode MEI 2011 OKTOBER 2011. Jurnal e-Biomedik (eBM), Volume 1(1): 45-49
[6]. Merentek, E.(2006). Resistensi Insulin Pada Diabetes Melitus Tipe 2. Cermin Dunia Kedokteran .(150)

[7]. Badan POM RI. (2006). Kepatuhan Pasien : Faktor penting dalam keberhasian Terapi. Vol.7 (5)

[8]. Mulyani, R.(2016). Hubungan Kepatuhan dengan Keberhasilan Terapi Berbasis Kombinasi Insulin dan Obat Antidiabetik Oral pada Pasien Diabetes Mellitus Tipe 2 di Instalasi Rawat Jalan Rumah Sakit Umum Daerah Ulin Banjarmasin. Prosiding Rakernas dan Pertemuan Ilmiah Tahunan Ikatan Apoteker Indonesia

[9]. Raditya,R.,dkk.(2015). Pengaruh pemberian Home care oleh apoteker pada pasien diabetes melitus. Jurnal Manajemen dan pelayanan Farmasi. Volume 5 (3)

[10]. Dinas kesehatan Provinsi Jawa Tengah.(2014). Profil kesehatan provinsi jawa tengah tahun 2014. Semarang

[11]. Info Diabetes Melitus. Data Statistik Jumlah Penderita Diabetes di Dunia versi WHO.(2012). Dipublikasikan 26 februari 2012.Website: http://indodiabetes.com/data-statistikjumlah-penderita-diabetes-di-dunia-versiwho.html

How to cited this article :

Najiha MR, Utaminingrum W, Wibowo MINA. 2017. Peran Homepharmacycare pada Pasien Diabetes Mellitus Tipe II Prolanis terhadap Tingkat Kepatuhan dan Keberhasilan Terapi di Bp Sentra Medika Lebaksiu Tegal, J. Trop. Pharm. Chem. (4)2. 59-64. 